Bibliography continued from previous page-S. Fazlullah, M.B.(Osmania), D.T.M. E H.

KUSSMAUL, A., and MAIER, R. (1866), Dtsch. Arch. klin. Med., LIVE, 484

LONG, D. A. (1954), ibid., i, 529.

LONG, D. A. (1955), Int. Arch. Allergy, N.Y., 6, 337.

LONG, D. A. (1956), Proc. roy. Soc. Med., 49, 205

LOVSHIN, L. L., and KERNOHAN, J. W. (1948), Arch. Int. Med., 82, 321 .

LUBENS, H. M. (1955), Ann Allergy, 13, 265.

LUMSDEN, C. E. (1949), Brain, 72, 198.

LUMSDEN, C. E. (1956), Proc. roy. Soc. Med., 49, 148.

MALAMUD, N., and FOSTER, B. D. (1942), Arch. Neurol. Psychiat., 47, 828 .

MCALPINE, D.' (1931), Lancet, i, 846.

MCALPINE, D. (I956), Practitioner, 176, 123.

MCCORMIĆK, R. V. (1950), F. Amer. med. Ass., 144, 1453.

MILLER, H. G. (1949), Proc. roy. Soc. Med., 42, 497.

MILLER, H. G. (1953), Brit. med. F., i, 846 .

MILLER, H. G. (1956), Proc. roy. Soc. Med., 49, 139.

MILLER, H. G., and EVANS, M. J. (1953), Quart. F. Med., 22, 347.

NEALE, A. V., and WHITFIELD, A. G. W. (r934), Brit. med. F., ii, ro4.

O'BRIEN, D. J., and STOREY, G. (1954), ibid., i, 792.

OPHULS, W. (1923), Arch. int. Med., 32, 870.
POLLEY, H. (1956), Brit. med. $\mathcal{F}_{., 1}$ ii, 15 r.

RICH, A.' R., and GREGORY, J. E. (1943), Bull. Fohns Hopk. Hosp., $72,65$.

RICH, A. R. (1946/47), Harvey Lecture, 42, 106.

RICH, A. R. (1942), Bull. Fohns Hopk. Hosp., 71, 123.

RUNGE, W., and MELZER, H. (r930), f.' Psych. Neurol. (Lpz.),

RUSSEL 298. D. S. (1937), F. Path. Bact., 45, 357.

RUSSELL, D. S. (1955), Brain, 78, 360.

SELYE, H., BELAND,' E., and SYLVESTER, O. (1944), Exp. Med. Surg., 2, 224.

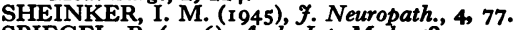

SPIEGEL, R. (1936), Arch. Int. Med., 58, 993 .

SQUIER, T. L., and MADISON, F. W. (1937), f. Allergy, 8, 143. TOWERS, A. G. (1955), Lancet, ii, 43

VESZPREMI, D., and JANCSO, M. (1903), Beitr. path. Anat.,

WAKSMAN, B. H., and ADAMS, R. D. (1955), f. exp. Med.,

WINKELMAN, N. W., and ECKEL, J. L. (1932), Arch. Neurol.

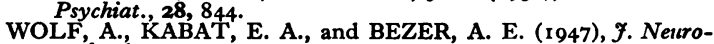
path., 6, 333 .

ZEEK, P.' M. (1952), Amer. F. clin. Path., 22, 77.

ZEEK, P. M. (1953), New Eng. Э. Med., 248, 764.

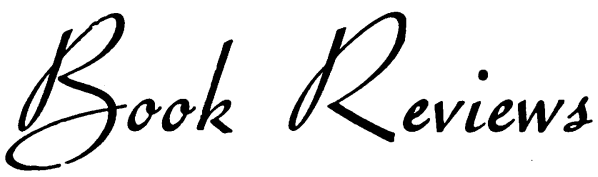

\section{A TEXTBOOK OF MENTAL DEFICIENCY}

By R. F. Tredgold, M.D., D.P.M., and K. Soddy, M.D., D.P.M. Ninth Edition. Pp .xv +480 , with $3 \mathrm{I}$ plates. London: Bailliere, Tindall \& Cox. 1956. 40s.

First published in 1908 , and now in its ninth edition, 'Tredgold's Mental Deficiency' still remains the best book on the subject in the English language. This new edition brings in some outstanding changes, however, all of them for the better, and this follows from Dr. Tredgold taking over the work from his father, the late Dr. A. F. Tredgold, with the assistance of his colleague, Dr. Soddy. While the authors have been careful to preserve the noteworthy features of the earlier editions, namely, the clinical descriptions, the rest of the book has been rewritten in the light of contemporary research and recent developments in the psychological theory of mental deficiency. A number of plates have been omitted, and others have been brought up to date; the latter is certainly overdue, for even the last post-war edition contained many photographs taken, to judge by the dress, half a century ago. The development of what has been called 'biosocial medicine'-particularly in the last decade-is reflected by the emphasis placed on the home environment of the defective, his education and rehabilitation, and in the sections on the sociological implications of mental deficiency in its community setting, the authors have made a most valuable contribution. It is perhaps a pity that the term ' amentia' finds support in this book for its increasing use. While not etymologically incorrect, the word has a different connotation on the Continent. The Italian amenza means, and is used for, confusional insanity, and elsewhere in Europe, and particularly Holland, amentia is regarded as this form of psychosis. If we must have a medical term to replace 'mental deficiency,' the generally acceptable term of oligophrenia would be preferable, particularly since this work enjoys such a high reputation abroad. Mental deficiency, in one aspect or another, touches almost every branch of medicine, and this classical text remains an essential reference book, while the innovations due to its change of authors outdate all previous editions and makes imperative their replacement.

\section{L.R.C.N.}

\section{PERIPHERAL VASCULAR DISORDERS}

By D. I. Abramson, M.D., F.A.C.P. Pp. $x v+537$, with 82 illustrations. London: Cassell \& Co. Ltd. 1957. £5 $5 \mathrm{~s}$.

Dr. Abramson is to be congratulated on this book which is an up-to-date practical guide to peripheral vascular disorders. As indicated by the title, diagnosis and treatment are the theme of the book with little discussion of pathology or aetiology. It is 
in those sections devoted to diagnosis that the book excels; they are packed full of practical knowledge, obviously written by a man of wide experience, and they will be of great value to clinicians. The treatment of peripheral vascular disorders is also discussed but, speaking as a surgeon, I feel that they are not as valuable, particularly in the surgical portions, as those sections devoted to diagnosis; for example, the approach to such problems as gangrene is too conservative, and some of the more recent methods of preventing amputation by arterial reconstruction are not discussed. Even so these chapters are good; they merely suffer by comparison with the better diagnostic chapters.

This book is strongly recommended.

\section{C.G.R.}

\section{GYNAECOLOGIC CANCER}

By James A. Corscaden, Ph.B., M.D. Second Edition. Pp. ix +546 , with I I 5 illustrations. London: Bailliere, Tindall \& Cox Ltd. 1956. 80 s.

This is a great book. It is one of the very few text books that is at the same time a thorough, serious monograph on an extremely difficult subject, and written so that the style is fluid and lucid and fascinating. It could not have been an easy book to write, for immense research has gone into it.

At the end of every chapter, there is a bibliography of, on an average, fifty or more references, and there are thirteen chapters.

But what shines through this book is the enthusiasm of the author.

Gynaecological cancer is there to treat and to cure, and cures are possible in very large numbers of cases, if diagnosis is early, thorough and accurate, and treatment early, rational and adequate.

In the chapter on cancer of the cervix; for instance, not only are all the sites of the possible primaries given and illustrated, together with their spread, but also all the known methods of diagnosis are stated and evaluated, as are the methods of treatment. The argument that always rages between radio-therapy and/or surgery is stated, and precise indications as to the treatment the author would use for particular types of cases. This is the essence of a good text book-that everybody's rational method is described, and the less experienced reader is given a chance of choosing; and yet given a didactic method that he himself can follow if the choice becomes too difficult for him to make.

This is probably one of the greatest gynaecological works to have been written in the last twenty years. It is worth reading from cover to cover, not only by specialists in gynaecology, although it is a must for them. Anyone into whose hands falls the possible early diagnosis of a single carcinoma of the female genital organs should have seen this book.
Everyone whose profession is to treat gynaecological cancer should possess a copy. Even such details as the role of the patient's family relations, the role of the menopause-artificial or naturaland the nature of cancer are dealt with humanly yet scientifically.

Careful perusal of the book has found no single fault in printing or proof reading, nor any argument with which serious disagreement can be reached.

E.E.P.

\section{CIBA FOUNDATION SYMPOSIUM BONE STRUCTURE AND METABOLISM}

Edited by G. E. W. Wolstenholme, O.B.E., M.A., M.B., B.Ch., and Cecilia M. O'ConNor, B.Sc. Pp. xii +299 , illustrated. London: J. \& A. Churchill Ltd. 1956. 45 s.

This edited record of a symposium attended by recognized authorities on the structure and metabolism of bone, is certain of a welcome from workers in these and in related fields. The twenty papers included in this book present the results of recent work on the mineral and organic structure of bone, and on subjects such as the mode of action of vitamin $\mathrm{D}$, and the role of the parathyroid glands The field covered is necessarily wide, but the contributions have been so arranged as to form connected account of recent developments. It is helpful, too, to have the discussion of each paper following the presentation of the paper itself, for these discussions often serve to clarify and expand any obscure points.

Although much of the work recorded here will be of interest primarily to the experimental worker, the clinician will find in it much to help him to an understanding of pathological conditions of bone. It is, for instance, of direct consequence to the clinician that the skeletal disturbance associated with steatorrhoea can no longer be attributed to defective absorption of vitamin D. Again, certain of the studies point the way to a better understanding of the processes involved in the healing of fractures and in the associated osteoporosis. It is particularly valuable for the research worker to find the contributors admitting and defining the limitations of their knowledge, for by doing this they show the lines along which further work should go.

While it would be invidious to single out for special mention any individual contributor to the symposium, it is clear that the part played by the Chairman, Dr. C. E. Dent, contributed greatly to its success. Acknowledgement should be made too, to the Ciba Foundation and to the Bone and Tooth Society, whose co-operation resulted in this very valuable meeting. The editors are to be congratulated on producing a permanent record of the symposium for the wider diffusion of so much interesting and stimulating material. 